\title{
Primary care in urban disadvantaged communities
}

\author{
Edited by Joe Kai and Chris Drinkwater \\ Radcliffe Medical Press 2004, 17 chapters, \\ 192 pages + index, \\ ISBN 1857754379
}

The delivery of health and social services for populations of disadvantaged people is a good indicator of the wellbeing and quality of life of any community. The principle of equity is usually proclaimed in the ideas of decision makers, but fails in reality. Policy makers are pressed with cost containing strategies and setting priorities and, unfortunately, these particularly vulnerable segments of the population are not on the list of priorities. In these times of post modernism, we are looking for more flexible and pragmatic, less conceptual, 'living' ways to supplement the gaps in the presently organized ways of health and social care. This book is about various small initiatives, realized through the projects, that deal with the demand oriented approach and integration of care for disadvantaged people. It offers many alternatives to the traditional pathways of care, toward continuity across the primary care interface.

Through 17 chapters, we examine how primary care is responding to the challenge of urban disadvantage, sharing the experience of more than 20 contributors, mostly working in the field of primary care. The different experiences, presented in separate chapters, have many connecting points. The authors aim to identify and explain the problems, and to assist in finding particular solutions and the best approaches to dealing with communities of disadvantaged people. Their experiences are precious for many target groups: public health professionals, primary care workers, patients and the public.

At the beginning of the book, the authors introduce us to the phenomena of urban regeneration, in connection with changes in healthcare systems. The 'way out' of the pessimistic view of the situation is in the empowerment of the social capital in the community and the development of the learning organizations, like West End Health Resource Centre. The following chapters provide very interesting examples of community projects for healthcare, illustrated with individual stories. The main focus of some projects is the social model of health. It is in accordance with the broader concept of health, in which the influencing factors extend into different areas, such as housing policy and income maintenance. That leads us to the further explanation of community-oriented approaches to health and community development.

Reading this book, one can distinguish the examples of health promotion activities and projects from examples of interesting efforts for integrated approach in the community.

Within this book there is a lot to read about different possibilities for health promotion in communities of disadvantaged persons. Nevertheless, not all projects from this group are equally important and informative. For example, The Flower 125 Club is a story of very 'local' significance (the project lasted for twenty weeks and involved up to fifteen young people aged 1116 years in workshops focused on different health issues). This is also the case with the 'ordinary story of inner city teamwork', from Foxwill, Community Education Training Programme-a support to the smoking cessation, and some other examples through different chapters.

In contrast, if the reader expects a good and applicable model of integration at the primary level, then Chapter 13 contains an excellent paper about the multidisciplinary community resource team approach in responding to the needs of elderly. With the same enthusiasm, Chapter 11 describes a project with a very witty name - 'Second Chancers'. It is an interesting community cardiac rehabilitation project, with a number of case examples. Chapter 7 describes the partnership between primary care organizations and local communities. A successful example of that partnership is the foundation of Community Action on Health, funded through primary care in Newcastle upon Tyne. This chapter concludes with the statement that the project has demonstrated the importance of engaging local communities and ensuring the participation of marginalized and minority groups. Chapter 12 contains an excellent paper about the necessity of a whole system approach in mental health services; good references, illustrative boxes and the recommendation for further reading, contribute to the quality.

Chapter 5 stands out from the two previously mentioned frameworks, introducing us to the causes of stress among general practitioners that are connected with working and living in deprived communities. As a part of the chapter, we learn about some possible individual interventions, such as coping skills training.

This book illuminates the necessity of a new approach to the assessment of needs within populations of dis- 
advantaged people. A positive attitude could provide a range of excellent and imaginative results, like some of the projects mentioned above. The idea of integration is beyond the simple united forces of medical and social care at the primary level, but also the promotion of active patient involvement in self-care. The importance of the active role of the patient is emphasized by the fact that those living in areas of disadvantage are not able to make healthy choices for themselves. The vision of the improvement is mostly based on a shared commitment between different parts of a society, not only organized systems, but more imaginative and alternative actors within a community. The authors of the book have successfully proved this statement with many well-chosen references (public health surveys, longitudinal studies). The integration of care is founded in a well-defined concept of community health and mainly understood as an important continuum of care through the present systems (health and social care), as well as the new solutions for organization.

This book introduces us to interesting authors, involved in teams, who felt needed, satisfied and encouraged to share this kind of commitment to working with people. They were trying to change things, to improve the quality of work with disadvantaged people and, consequently, to raise public trust and respect in primary health care professionals. This book is one big step toward that goal.

Bojana Matejic, MD Assistant Professor of Social Medicine, Institute for Social Medicine, Medical Faculty, University of Belgrade, Serbia and Montenegro 